\title{
Correction to: Aortic calcification is associated with non-infective rather than infective postoperative complications following colorectal cancer resection: an observational cohort study
}

\author{
Katrina A. Knight ${ }^{1}$ (D) Chui Hon Fei ${ }^{2} \cdot$ Kate F. Boland $^{2} \cdot$ Daniel R. Dolan ${ }^{2} \cdot$ Allan M. Golder $^{1} \cdot$ Donald C. McMillan $^{1} \cdot$ \\ Paul G. Horgan ${ }^{1}$ - Douglas H. Black ${ }^{1}$. James H. Park ${ }^{1}$ - Campbell S. D. Roxburgh ${ }^{1}$
}

Published online: 8 February 2021

(C) European Society of Radiology 2021

\section{Correction to: European Radiology} https://doi.org/10.1007/s00330-020-07189-7

The original version of this article, published on 17 November 2020, unfortunately contained two mistakes. The following corrections have therefore been made in the original:

Firstly, in the second paragraph of the "Material and methods" section, the corresponding reference for the sentence "Anastomotic leak was defined as a communication between the intra- and extraluminal compartments arising from a defect in the intestinal wall at the anastomotic site [17]." should not be reference 17 but a new consecutive reference [42]: Kulu Y, Ulrich A, Bruckner T, Contin P, Welsch T, Rahbari NN, Büchler MW, Weitz J; International Study Group of Rectal Cancer. Validation of the International Study Group of Rectal Cancer definition and severity grading of anastomotic leakage. Surgery. 2013 Jun;153(6):753-61.

Secondly, reference [38] was incorrect. It should be: Roxburgh CSD, Strombom P, Lynn P, Cercek A, Gonen M, Smith JJ, Temple LKF, Nash GM, Guillem JG, Paty PB, Shia J, Vakiani E, Yaeger R, Stadler ZK, Segal NH, Reidy D,
Varghese A, Wu AJ, Crane CH, Gollub MJ, Saltz LB, GarciaAguilar J, Weiser MR. Changes in the multidisciplinary management of rectal cancer from 2009 to 2015 and associated improvements in short-term outcomes. Colorectal Dis. 2019 Oct;21(10):1140-1150.

The corrected references are given below. The original article has been corrected.

\section{References}

38. Roxburgh CSD, Strombom P, Lynn P et al (2019) Changes in the multidisciplinary management of rectal cancer from 2009 to 2015 and associated improvements in short-term outcomes. Colorectal Dis 21(10): $1140-1150$

42. Kulu Y, Ulrich A, Bruckner T et al (2013) Validation of the International Study Group of Rectal Cancer definition and severity grading of anastomotic leakage. Surgery 153(6):753-761

Publisher's note Springer Nature remains neutral with regard to jurisdictional claims in published maps and institutional affiliations.

The online version of the original article can be found at https://doi.org/ $10.1007 / \mathrm{s} 00330-020-07189-7$

Katrina A. Knight

Katrina.Knight@glasgow.ac.uk

1 Academic Unit of Colorectal Surgery, University of Glasgow, Level 2, New Lister Building, Glasgow Royal Infirmary, 10 - 16 Alexandra Parade, Glasgow G31 2ER, UK

2 School of Medicine, Wolfson Medical School Building, University of Glasgow, Glasgow G12 8QQ, UK 